Jurnal Pengabdian kepada Masyarakat

\title{
Pelatihan Desain Pembelajaran dengan E-learning Berbasis LMS Moodle
}

\author{
Parulian Silalahi ${ }^{1 *}$, Charlota Agripina ${ }^{2}$, Yang $_{\text {Agita }}{ }^{3}$ \\ ${ }^{1,2,3}$ Politeknik Manufaktur Negeri Bangka Belitung \\ *paruliansilalahi1964@gmail.com
}

\author{
Kata Kunci: \\ e-learning, \\ evaluasi, \\ daring, LMS \\ Moodle.
}

\begin{abstract}
Abstrak Moodle merupakan sistem manajemen pembelajaran yang dapat mendukung implementasi e-learning. Meskipun penggunaan aplikasi Moodle berkembang pesat, namun masih banyak guru yang belum dapat menggunakannya. Tujuan dari pengabdian ini adalah untuk melatih guru agar memiliki pengetahuan dan keterampilan dalam mendesain dan mengembangkan pembelajaran dengan Elearning berbasis LMS Moodle. Pelatihan ini diberikan pada guru SMP Maria Goretti Sungailiat Bangka. Metode pelaksanaan pengabdian dilakukan dengan tiga phase: phase 1. persiapan; phase 2. pelaksanaan; dan phase 3. Evaluasi. Pelaksanaan pengabdian dilakukan secara tatap muka dan daring. Melalui tatap muka pelatihan diberikan dengan ceramah dan demonstrasi yang diselenggarakan selama 3 kali pertemuan pada bulan Juli 2020 dengan jumlah yang guru yang ikut dalam pelatihan ini sebanyak 10 orang. Secara daring diberikan dengan menggunakan aplikasi Moodle. Hasil pelatihan menunjukkan bahwa pengetahuan guru bertambah dan telah memiliki keterampilan dalam mendesain dan mengembangkan pembelajaran menggunakan aplikasi E-learning LMS Moodle bertambah.
\end{abstract}

\section{Keywords:} e-learning, evaluation, online, LMS Moodle

\begin{abstract}
Moodle is a learning management system that can support e-learning implementation. Although the use of the Moodle application is growing rapidly, there are still many teachers who are not able to use it. The purpose of this service is to train teachers to have the knowledge and skills in designing and developing learning with E-learning based on Moodle LMS. This training was given to SMP Maria Goretti Sungailiat Bangka teachers. The method of implementing the service is carried out in three phases: phase 1. preparation; phase 2. implementation; and phase 3. Evaluation. The service is carried out face-to-face and online. Through face-to-face training, lectures and demonstrations were held for 3 meetings in July 2020 with 10 teachers participating in this training. Online provided using the Moodle application. The results of the training show that the teacher's knowledge increases and has skills in designing and developing learning using the Moodle LMS E-learning application.
\end{abstract}

\section{PENDAHUluaN}

Sesuai dengan amanat Undang-Undang Nomor 14/2005 tentang guru dan dosen yang menyatakan bahwa setiap guru memiliki kompetensi sesuai dengan bidang tugasnya. Peraturan Pemerintah Nomor 74 Tahun 2008, Bab II bagian Kesatu Pasal 3 ayat 6b, menyatakan bahwa guru harus menggunakan teknologi komunikasi dan informasi secara fungsional.

Dalam dekade terakhir ini, penggunaan Teknologi Informasi dan Komunikasi (TIK) berkembang pesat dan telah mendominasi dunia pendidikan di seluruh dunia. Cepatnya perkembangan teknologi tersebut telah menjadikan perubahan yang dinamis di semua tingkat pendidikan mulai dari sekolah dasar sampai perguruan tinggi. Penggunaan teknologi dalam pendidikan meningkat secara dramatis (Fifoot 2000; Mann 2000). Hasil penelitian diberbagai bidang pendidikan menunjukkan bahwa secara umum penggunaan 
teknologi dapat mendukung metode pembelajaran yang inovatif (Miner 2004). Riasati at al (2012) mengemukakan bahwa dengan menggunakan integrasi teknologi seperti penggunaan aplikasi LMS Moodle dalam pembelajaran kolaboratif yang mengedepankan lingkungan penuh dengan kerja sama, berinteraksi satu sama lain dan komunikasi dapat dilakukan dengan baik. Menurut Levin \& Wadmany (2008), guru dapat mengintegrasikan teknologi dengan berbagai tujuan seperti pelatihan formal, waktu dan praktik serta peluang pengembangan profesional. Selain itu teknologi juga dapat meningkatkan kemampuan kognitif dan afektif siswa (Frigaard, 2002; Timucin 2006). Manfaat lainnya juga dikemukakan oleh $\mathrm{Che} \mathrm{Ku}$ (2014) bahwa teknologi dapat digunakan untuk mengelola sumber daya dan membuat materi pembelajaran.

Sayadian (2009) mengemukakan bahwa meskipun penelitian menunjukkan bahwa teknologi adalah sarana yang efektif untuk meningkatkan peluang pendidikan dan diyakini sangat membantu guru dalam mengajar dan belajar, namun banyak guru tidak menggunakan teknologi sebagai sistem pembelajaran atau mengintegrasikan teknologi ke dalam kurikulum mereka. Purcell, Heaps, Buchanan, \&Friedrich (2013) menyatakan bahwa mayoritas guru masih kurang aktif. Di samping itu implementasi penggunaan teknologi dalam proses pembelajaran masih mengalami tantangan dalam mengadopsi teknologi sebagai media pembelajaran (Hew \& Brush, 2006). Guru belum sepenuhnya melakukan inovasi dalam memanfaatkan potensi teknologi. yang ada untuk mengubah praktik pembelajaran yang dapat membawa lingkungan belajar yang didukung oleh teknologi (Lim, 2001). Hal ini juga dialami oleh guru SMP Maria Goretti Sungailiat Bangka.

\subsection{Analisis Situasi Mitra}

Analisis situasi mitra dilakukan pada SMP Maria Goretti beralamat di jalan Maria Goretti No 7 Sungailiat Bangka. SMP Maria Goretti berdiri sejak 29 September 1986. Sekolah ini cukup dikenal luas oleh masyarakat. Letak geografis yang strategis berada dekat dengan jalan raya Sungailiat. Kondisi sekolah secara umum baik. Sekolah memiliki sarana dan prasarana yang memadai dan cukup untuk menyelenggarakan pendidikan dengan baik. Personil tenaga pendidik sebanyak 10 orang yang sebagian besar berijazah $\mathrm{S} 1$ dan tenaga kependidikan sebanyak 3 orang dalam rangka mendukung kemajuan sekolah. Prestasi sekolah saat ini dinilai baik dengan akreditasi " $A$ ".

Upaya untuk tetap mempertahankan prestasi sekolah terus dilakukan dengan menyediakan sarana dan prasarana sekolah. Salah satu yang telah dilakukan oleh sekolah adalah memfasilitasi guru dan siswa melalui penyediaan laboratorium komputer serta penyediaan jaringan internet. Meskipun saranah ini sudah tersedia, namun masih belum dimanfaatkan dengan optimal. Hal ini disampaikan oleh kepalah sekolah saat diskusi mengenai upaya sekolah untuk meningkatkan kompetensi para guru menghadapi era digital saat ini, seperti yang terlihat pada Gambar 1 berikut.

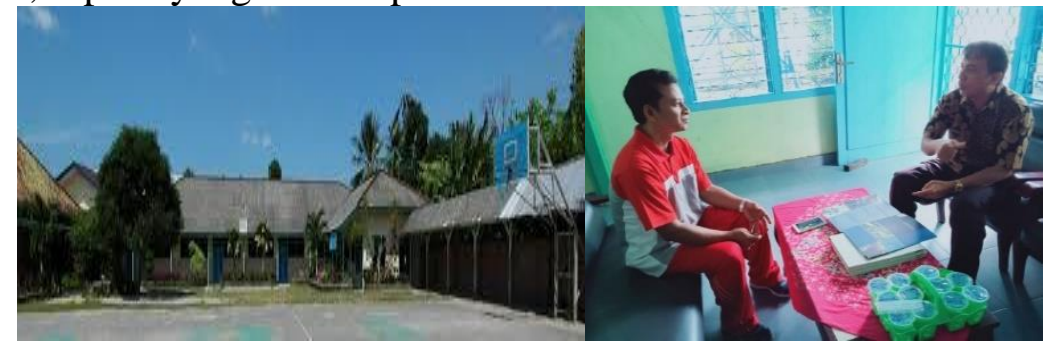

Gambar 1. Saat diskusi dengan kepala sekolah 


\subsection{Permasalahan Mitra}

Berdasarkan analisis terhadap situasi keadaan lingkungan sekolah mitra, permasalahan yang dihadapi oleh sekolah adalah bahwa para guru masih lebih dominan mengajar dengan cara tradisional. Beberapa hal yang menyebabkan guru tidak menggunakan teknologi, antara lain karena kurangnya pemahaman tentang dampak integrasi teknologi pada proses pembelajaran yang dilakukan oleh guru pada siswa. Selain itu mereka kurang memahami tentang kemudahan teknologi dalam pembelajaran, menyediakan metode yang jauh lebih mudah untuk digunakan, misalnya dalam pengembangan kurikulum, perencanaan belajar, memotivasi siswa, menelusuri tingkat keberhasilan siswa dan lain sebagainya.

Kondisi para guru yang ada saat ini masih belum optimal dalam merencanakan, mengembangkan, serta mengimplementasikan pembelajaran dengan menggunakan aplikasi teknologi informasi dan komunikasi (TIK) seperti LMS Moodle dalam pembelajaran. Beberapa faktor penyebab kurang berkembangnya pemanfaatan komputer dalam pembelajaran dengan menggunakan aplikasi teknologi diantaranya adalah: (1) kurangnya pengetahuan tentang pedagogi yang mendukung pembelajaran dengan mengintegrasikan komputer; (2) kurangnya pengetahuan dalam pemanfaatan internet sebagai sumber belajar; (3) kurangnya pengetahuan dalam mendesain pembelajaran berbasis teknologi informasi dan komunikasi; dan (4) kurangnya pengetahuan tentang membuat materi pembelajaran berbasis web.

Dengan demikian dibutuhkan suatu program pengembangan profesional bagi guru yang dapat meningkatkan kemampuan mereka dalam mendesain dan mengembangkan pembelajaran dengan menggunakan aplikasi teknologi seperti LMS Moodle.

\section{METODE}

Tujuan kegiatan program pengabdian masyarakat ini adalah membantu guru mengembangkan pengetahuan dan keterampilan yang diperlukan untuk membantu siswa belajar secara daring. Untuk menyelesaikan masalah yang dihadapi agar tujuan pengabdian yang telah ditetapkan tercapai dengan baik, maka dilakukan serangkaian kegiatan, mulai dari analisis situasi, persiapan, pelaksanaan hingga evaluasi dari pelaksanaan program pengabdian serta pendampingan yang diberikan kepada guru. Secara umum tahapan kegiatan program pengabdian masyarakat yang akan dilakukan dibagi dalam tiga phase seperti berikut:

\section{Phase 1. Persiapan}

Dalam tahap ini, pengabdi melakukan analisis situasi pada mitra. Analisis dimulai dengan mengidentifikasi karakteristik guru, pengalaman dan keterampilan dalam menggunakan teknologi dalam pembelajaran, seperti aplikasi LMS Moodle. Untuk mendapatkan informasi tersebut dilakukan dengan wawancara dengan kepala sekolah dan guru.

Dari informasi yang diperoleh, kemudian dilanjukan dengan menentukan desain lengkap dari tujuan pengabdian yang akan diberikan. Tahap desain adalah proses sistematis dari perencanaan, mengidentifikasi dan menentukan desain lengkap dari tujuan pengabdian yang akan diberikan. Secara umum pada phase persiapan terdiri dari: konten pelatihan, metodologi pelatihan, media, latihan untuk peserta, dan kriteria penilaian. Kegiatan berikutnya pada persiapan ini adalah melakukan pengembangan berupa kegiatan perakitan dan memproduksi material serta pembuatan aplikasi LMS Moodle. 


\section{Phase 2. Implementasi}

Tahap implementasi merupakan pelaksanaan program pelatihan dan produk akhir yang dikembangkan berdasarkan kebutuhan guru yang mengikuti pelatihan. Hasil produk berupa modul dan website yang telah dipersiapkan sebelumnya, akan digunakan pada saat pelatihan berlangsung.

\section{Phase 3. Evaluasi}

Tahap evaluasi adalah proses sistemik, mempertimbangkan umpan balik dari peserta pelatihan. Umpan balik yang dikumpulkan selama tahap ini mengukur reaksi, mengidentifikasi bagian mana yang sulit dipelajari oleh peserta pelatihan dari materi yang diberikan, menentukan efektivitas dan kualitas penyajian materi pelatihan yang digunakan dalam rangka untuk menyempurnakan program pelatihan yang disusun. Pada akhir program peserta pelatihan akan diberikan kuesioner yang bertujuan untuk menilai kegiatan program pengabdian masyarakat berupa pelatihan yang diberikan pada guru.

\section{HASIL DAN PEMBAHASAN}

Program pengabdian masyarakat ini dilaksanakan di SMP Maria Goretti terletak di wilayah Kecamatan Sungailiat Bangka. Sebagaimana yang dikemukakan sebelumnya bahwa tujuan utama dari program kegiatan ini adalah untuk meningkatkan pengetahuan dan keterampilan guru dalam mendesain dan mengembangkan pembelajaran e-learning berbasis LMS Moodle. Hasil kegiatan dari program ini diuraikan sebagai berikut:

\section{Phase 1. Persiapan}

Dalam tahap ini, pengabdi melakukan analisis situasi mitra melalui diskusi dengan kepala Sekolah SMP Maria Goretti. Pada tahap analisis dimulai dengan mengidentifikasi karakteristik guru, pengalaman dan keterampilan dalam menggunakan aplikasi LMS Moodle dalam pembelajaran. Berdasarkan hasil diskusi dengan kepala sekolah, diperoleh informasi bahwa pengetahuan serta keterampilan guru tentang LMS Moodle berada pada kategori sangat kurang. Selain itu pengetahuan tentang bagaimana pengetahuan guru tentang penerapan pedagogi untuk pembelajaran secara daring masih kurang. Berdasarkan permasalahan tersebut, maka pengabdi dan kepala sekolah sepakat memutuskan untuk dilakukan suatu kegiatan pelatihan. Selanjutnya didesain suatu kegiatan pelatihan mulai dari desain materi sampai pengembangan web yang akan diberikan kepada guru. Pada tahap ini, semua materi yang telah tersusun dalam modul maupun pada website, dan siap untuk digunakan. Alamat elearning yang dikembangkan oleh tim pengabdi adalah: (http://blendedlearning-smp.mariagoretti.bang-ka.id/) dengan tampilan seperti Gambar 2. Berikut.

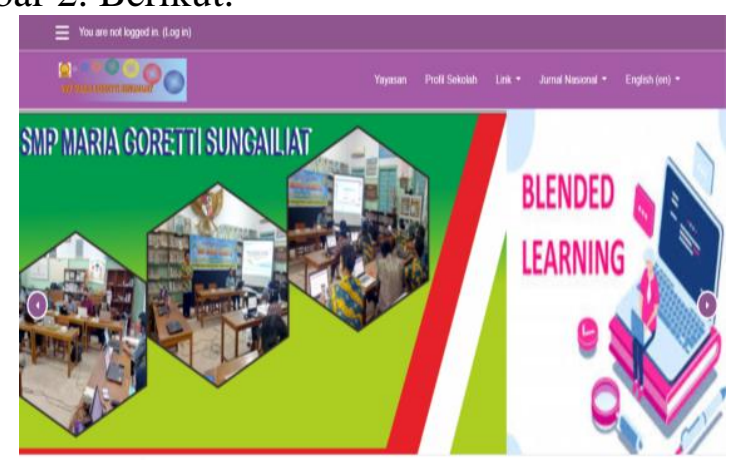

Gambar 2. Tampilan awal alamat web blended learning SMP Maria Goretti 


\section{Phase 2. Implementasi}

Tahap implementasi adalah tahapan di mana program pelatihan dan produk akhir yang dikembangkan benar-benar dilaksanakan. Hasil produk berupa modul dan website yang telah dipersiapkan disajikan kepada peserta pelatihan. Kegiatan pelatihan LMS Moodle yang diberikan kepada guru dari tanggal 16 sampai 18 Juli 2020. Salah satu gambar kegiatan dapat dilihat pada gambar 3. berikut:

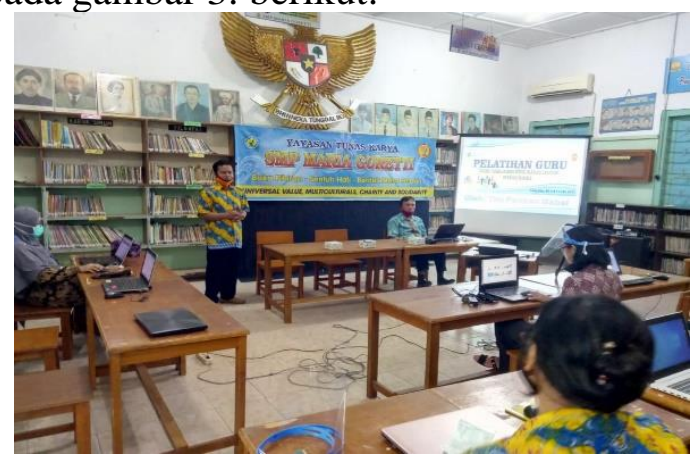

Gambar 3. Pelaksanaan pelatihan LMS MOODLE pada guru SMP Maria Goretti

\section{Phase 3. Evaluasi}

Tahap evaluasi adalah proses sistemik, mempertimbangkan umpan balik dari peserta pelatihan. Umpan balik yang dikumpulkan selama tahap ini mengukur reaksi, mengidentifikasi bagian mana yang sulit dipelajari oleh peserta pelatihan dari materi yang diberikan, menentukan efektivitas dan kualitas penyajian materi pelatihan yang digunakan dalam rangka untuk menyempurnakan program pelatihan yang disusun. Pada akhir program peserta pelatihan diberikan kuesioner dengan menggunakan skala likert dengan kriteria sebagai berikut:

Skor 1 : sangat tidak setuju/sangat kurang

Skor 2 : tidak setuju/kurang

Skor 3 : cukup

Skor 4 : setuju/baik

Skor 5 : sangat setuju/sangat baik

Kuesioner ini bertujuan untuk melihat efektifitas dari pelatihan yang diberikan. Hasil analisis dari kuesioner dapat dilihat seperti table 1. berikut ini:

Tabel 1. Hasil evaluasi pelatihan desain pembelajaran berbasis LMS Moodle

\begin{tabular}{llcccc}
\hline \multirow{2}{*}{ No } & \multicolumn{1}{c}{ Komponen Indikator } & \multicolumn{5}{c}{ Skor } \\
\cline { 3 - 5 } I & Efektivitas Pelatihan & 1 & 2 & 4 & 5 \\
\hline 1 & Tujuan pelatihan dinyatakan dengan jelas & $25 \%$ & $62,5 \%$ & $12,5 \%$ \\
\hline 2 & $\begin{array}{l}\text { Materi yang tercakup dalam program } \\
\text { relevan dengan pekerjaan saya }\end{array}$ & $12,5 \%$ & $50 \%$ & $37,5 \%$ \\
\hline 3 & $\begin{array}{l}\text { Materi dipresentasikan dengan cara yang } \\
\text { menarik }\end{array}$ & $12,5 \%$ & $75 \%$ & $12,5 \%$ \\
\hline 4 & $\begin{array}{l}\text { Instruktur memberikan pelatihan secara } \\
\text { efektif }\end{array}$ & $37,5 \%$ & $50 \%$ & $12,5 \%$ \\
\hline
\end{tabular}




\begin{tabular}{|c|c|c|c|c|}
\hline 5 & $\begin{array}{l}\text { Instruktur mempersipakan pelatihan dengan } \\
\text { baik }\end{array}$ & $12,5 \%$ & $62,5 \%$ & $25 \%$ \\
\hline 6 & $\begin{array}{l}\text { Alokasi waktu yang digunakan cukup } \\
\text { efektif. }\end{array}$ & $37,5 \%$ & $50 \%$ & $12,5 \%$ \\
\hline 7 & $\begin{array}{l}\text { Saya akan dapat menerapkan sebagian besar } \\
\text { materi untuk pekerjaan saya }\end{array}$ & $25 \%$ & $62,5 \%$ & $12,5 \%$ \\
\hline 8 & $\begin{array}{l}\text { Ada keseimbangan yang serasi antara } \\
\text { presentasi yang diberikan dengan } \\
\text { keterlibatan peserta }\end{array}$ & $25 \%$ & $75 \%$ & \\
\hline 9 & $\begin{array}{l}\text { Saya merasa melalui pelatihan ini akan } \\
\text { membantu } \\
\text { saya melakukan pekerjaan saya dengan lebih } \\
\text { baik }\end{array}$ & $25 \%$ & $50 \%$ & $25 \%$ \\
\hline 10 & $\begin{array}{l}\text { Ruang pelatihan dan peralatan yang } \\
\text { digunakan memadai }\end{array}$ & $25 \%$ & $75 \%$ & \\
\hline
\end{tabular}

Tabel 1 menunjukkan bahwa seluruh komponen indikator berada pada kategori cukup hingga sangat baik. Hal ini menunjukkan bahwa secara keseluruhan hasil dari pelatihan yang diberikan berada pada kategori baik. Melalui pelatihan ini para guru telah mampu menerapkan aplikasi Moodle dalam pembelajaran mereka.

\section{KESIMPULAN}

Kegiatan pelatihan LMS Moodle yang diberikan kepada guru SMP Maria Goretti Sungailiat secara umum dapat terlaksana dengan baik. Melalui pelatihan ini terbukti dapat membantu peningkatan pengetahuan dan keterampilan para guru dalam mendesain dan mengembangkan pembelajaran dengan e-learning berbasis LMS Moodle. Selain itu, hal utama yang mendukung berhasilnya kegiatan ini adalah dengan komitmen kepala sekolah dan semangat guru yang mau bekerja keras hingga mereka dapat mengimplementasikannya di kelas.

\section{Ucapan Terima Kasih}

Kami berterimakasih kepada Direktur Politeknik Manufaktur Negeri Bangka Belitung yang telah menyediakan dana kegiatan pengabdian masyarakat tahun 2020. Tidak lupa juga kami ucapkan terima kasih kepada kepala sekolah SMP Maria Goretti Sungailiat sebagai mitra yang telah mendukung lancarnya pelaksanaan program yang diberikan.

\section{Daftar Pustaka}

Che Ku Nuraini Che Ku Mohd, Faaizah Shahbodin, Naim Che Pee (2014). Exploring the Potential Technology in Personalized Learning Environment (PLE). J. Appl. Sci. \& Agric., 9(18): 61-65.

Fifoot, B. (2000).The new task of the computer-able teacher. Journal of the QLD Society for Information Technology in Education 75: 18-19.

Frigaard, A. (2002). Does the computer lab improve student performance on vocabulary, grammar, and listening comprehension? ERIC Document Reproduction Service No. ED476749. 
Hew, K.F. \& Brush, T. (2006). Integrating technology into K-12 teaching and learning: current knowledge gaps and recommendations for future research. Education Technology Research Development, 223-252.

Levin, T., \& Wadmany, R. (2008). Teachers' views on factors affecting effective integration of information technology in the classroom: Developmental scenery. Journal of Technology and Teacher Education 16 (2): 233-263.

Lim, C.P. (2001). Object of the activity systems as a major barrier to the creative use of ICT in schools. Australian Journal of Educational Technology, 17(3), 295-312.

Mann, B. (2000). Internet provision of enrichment opportunities to school and home. Journal of the Australian Council for Educational Computing 15: 17-21.

Miner, T. (2004). Using technology to enhance learning: Instructor- or StudentModerated Discussion Boards: Which are more effective? Available from: http://www.cccone.org/scholars/0405/TomMiner_final_report.pdf

Riasati, J., M., (2012). Technology in Language Education: Benefits and Barriers. Journal of Education and Practice Vol 3, No 5.

Sayadian, S. (2009). Exploring The Factors Influencing UPM English Language Faculty Members' Adoption And Integration Of Web-Based Instruction (WBI). Journal of College Teaching \& Learning 6 (6).

Timucin, M. (2006). 'Implementing CALL in the EFL context'. ELT Journal 60 (3): 262-271. 